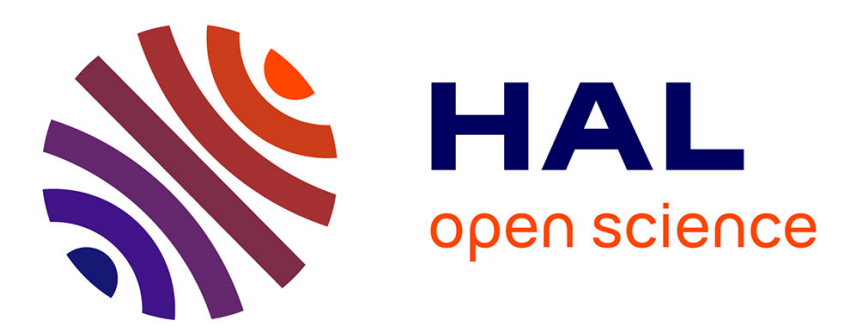

\title{
A reappraisal of shear wave splitting parameters from Italian active volcanic areas through a semiautomatic algorithm
}

Francesca Bianco, Lucia Zaccarelli

\section{- To cite this version:}

Francesca Bianco, Lucia Zaccarelli. A reappraisal of shear wave splitting parameters from Italian active volcanic areas through a semiautomatic algorithm. Journal of Seismology, 2008, 13 (2), pp.253-266. 10.1007/s10950-008-9125-z . hal-00478438

\section{HAL Id: hal-00478438 \\ https://hal.science/hal-00478438}

Submitted on 30 Apr 2010

HAL is a multi-disciplinary open access archive for the deposit and dissemination of scientific research documents, whether they are published or not. The documents may come from teaching and research institutions in France or abroad, or from public or private research centers.
L'archive ouverte pluridisciplinaire HAL, est destinée au dépôt et à la diffusion de documents scientifiques de niveau recherche, publiés ou non, émanant des établissements d'enseignement et de recherche français ou étrangers, des laboratoires publics ou privés. 


\title{
A reappraisal of shear wave splitting parameters from Italian active volcanic areas through a semiautomatic algorithm
}

\author{
Francesca Bianco $\cdot$ Lucia Zaccarelli
}

Received: 6 June 2007 / Accepted: 18 December 2007 / Published online: 11 September 2008

(C) Springer Science + Business Media B.V. 2008

\begin{abstract}
Shear wave splitting parameters represent a useful tool to detail the stress changes occurring in volcanic environments before impending eruptions. In the present paper, we display the parameter estimates obtained through implementation of a semiautomatic algorithm applied to all useful datasets of the following Italian active volcanic areas: Mt. Vesuvius, Campi Flegrei, and Mt. Etna. Most of these datasets have been the object of several studies (Bianco et al., Annali di Geofisica, XXXXIX 2:429-443, 1996, J Volcanol Geotherm Res 82:199-218, 1998a, Geophys Res Lett 25(10):1545-1548, 1998b, Phys Chem Earth 24:977-983, 1999, J Volcanol Geotherm Res 133:229-246, 2004, Geophys J Int 167(2):959-967, 2006; Del Pezzo et al., Bull Seismol Soc Am 94(2):439-452, 2004). Applying the semiautomatic algorithm, we confirmed the results obtained in previous studies, so we do not discuss in much detail each of our findings but give a general overview of the anisotropic features of the investigated Italian volcanoes. In order to make a comparison among the different volcanic areas, we present our results in terms of the main direction
\end{abstract}

F. Bianco $(\varangle) \cdot$ L. Zaccarelli

Istituto Nazionale di Geofisica e Vulcanologia,

Sezione di Napoli-Osservatorio Vesuviano,

Via Diocleziano 328, 80124, Naples, Italy

e-mail: bianco@ov.ingv.it of the fast polarization $(\varphi)$ and percentage of shear wave anisotropy $(\xi)$.

Keywords Shear wave splitting parameters • Temporal variations • Volcano seismology • Semiautomatic techniques

\section{Introduction}

Shear wave splitting is the elastic equivalent of the well-known phenomenon of optical birefringence. A shear wave propagating through an anisotropic volume splits into two $S$-waves $\left(\mathrm{qS}_{1}\right.$ and $\left.\mathrm{qS}_{2}\right)$ that travel with different velocities and different polarization directions. This process generates two observables: $T_{\mathrm{d}}$ is the time delay between the two split $\mathrm{S}$-waves, and $\varphi$ is the polarization direction of the faster one, $\mathrm{qS}_{1}$.

Seismic anisotropy is widely observed in the upper crust regardless of the tectonic setting. This phenomenon has been interpreted as occurring in zones of fluid-filled cracks, microcracks, or preferentially oriented pore spaces. The time evolution of anisotropic distribution of microcracks due to a differential stress, according to the nonlinear anisotropic poroelasticity (APE) model, is explained by fluid migration along pressure gradients between neighboring microcracks and pores (Crampin and Zatsepin 1997; Zatsepin and Crampin 1997). Stress intensity variations cause 
modifications of the fluid mobility and consequently of the anisotropic characteristics of the medium. In this framework, the shear wave splitting parameters, $T_{\mathrm{d}}$ and $\varphi$, are indicators of the stress field in the upper crust. Time delay variations are related to changes in microcrack density and aspect ratio, while the polarization directions of the two S-waves interchange $\left(90^{\circ}\right.$ flip of $\varphi$ ) when the system reaches the overpressurized regime (Crampin et al. 2004 and references therein).

Shear wave splitting parameters have been studied in several volcanic environments such as Hawaii (Booth et al. 1992; Munson et al. 1995) and Long Valley Caldera (Savage et al. 1990). Changes in shear wave splitting have been observed during the 1989 and the 2001 eruption at Mt. Etna, Sicily (Bianco et al. 1998b, 2006), before the 1996 eruption of Mount Ruapehu, New Zealand (Miller and Savage 2001; Gerst and Savage 2004), before the 1996 October eruption at Vatnajökull, Iceland (Volti and Crampin 2003), and before the M 3.6 earthquake at Mt. Vesuvius, 1999 October (Del Pezzo et al. 2004).

The main goals of our analysis are: (1) to improve the splitting parameter estimation for monitoring purposes; (2) to define $T_{\mathrm{d}}$ and $\varphi$ background values (i.e., out of eruptive periods); and (3) to look for temporal variation of the two observables and its relationship with volcanic activity.

Regarding the first point, we set up a semiautomatic procedure for measuring the splitting parameters in quasi-real time. Regarding points (2) and (3), we performed shear wave splitting measurements on local earthquakes recorded in the following Italian active volcanoes: Vesuvius, Campi Flegrei, and Etna.

Mt. Vesuvius is a stratovolcano located in the Campanian Plain (southern Italy) that experienced various regimes of eruptive activity from effusive to Plinian. Its last eruption occurred in March, 1944 and was a mild effusive event that concluded a period of almost continuous activity dating back to 1631. Since the 1944 eruption ended, the volcano has started a period of quiescence that seems to indicate a closure of its conduit. Up to the time of writing, Vesuvius activity consists of low seismicity and a little degassing at the crater top. We found splitting parameter variations from the background values during two seismic swarms, in 1996 and 1999, in which the largest earthquakes were M 3.4 and M 3.6, respectively.

Campi Flegrei is a resurgent caldera in southern Italy. Its formation has been related to two main explosive eruptions occurred about 38 and $12 \mathrm{ky}$ ago. The most recent activity in 1538 has been the formation of a 200-m-high spatter cone, preceded by a ground uplift of several meters. After this event, the caldera floor started sinking continuously and aseismically. This general trend is occasionally interrupted by faster resurgence episodes accompanied by earthquake swarms. We measured the splitting parameters during the three uplifts: 1982-1984 (180 cm of deformation); 2000 (6 $\mathrm{cm}$ of deformation); and 2005-2006 (3 cm of deformation). We found a complex pattern for both splitting parameters in both spatial and temporal domains.

Mt. Etna rises in the NE part of Sicily, Italy. The volcano has experienced many eruptions, and its almost persistent seismicity makes it a natural laboratory for volcano-seismic studies. We calculated the splitting parameters searching for their variations related to the 1988, 1989, and 2001 eruptions. The background value of $\varphi$ is parallel to the direction of the compressive stress field acting on the area, but it shows some variation especially before or during the eruptions. Also the time delays changed, depending on the periods considered and on the eruptive activity.

It has been possible to test the validity of this new semiautomatic method through the comparison of our results with those obtained in previous works for the same datasets. We interpret the observed time variations of the splitting parameters as indicators of complex stress changes, discussing their role as precursors of critical events such as major earthquakes or eruptions in the investigated areas.

\section{Methodology}

We first applied a rigorous selection on the seismic records according to the following criteria: (1) clear shear wave onsets with high signal-to-noise 
ratios: $\mathrm{S} / \mathrm{N}>6$ and (2) incidence angles strictly inside the shear wave window (theoretically $35^{\circ}$ ) to ensure no interaction with the free surface. To obtain the signal-to-noise ratio, we measured the noise amplitude before the $\mathrm{P}$-wave onset on all three components. We estimated the two splitting parameters through the implementation of a semiautomatic algorithm. This method minimizes subjectivity and reduces the analysis time required with no loss in accuracy. The semi-automation, in fact, consists of a first step of $\mathrm{P}$ and $\mathrm{S}$ manual picking, a procedure that needs the precision of an expert eye, and a second step of determination of the two measures: leading polarization and time delay. There exist many ways for estimating the splitting parameters, all of them have different qualities and validity ranges (Crampin and Gao 2006). We have chosen those with few requirements of intervention by the user, even though our analysis system allows easy interaction with screen images to check the results step by step.

We constructed a Matlab algorithm (versatile and user-friendly) that requires as input the previously selected event seismograms, their hypocenter locations, and $\mathrm{P}$ and $\mathrm{S}$ arrival times. The code evaluates the covariance matrix of a signal portion and diagonalizes it. The horizontal projection of the eigenvector corresponding to the maximum eigenvalue defines the leading polarization direction, $\varphi$ (expressed in degrees from the North). Both $\mathrm{N}$ and $\mathrm{E}$ components are then rotated to parallel and orthogonal to this azimuth, allowing the distinction between fast and slow waves. Finally, it cross-correlates these two signals whose maximum value occurs at a time lag equal to the $\mathrm{qS}_{1}-\mathrm{qS}_{2}$ delay, $T_{\mathrm{d}}$. Note that all results are checked in particle-motion diagrams (hodograms) to avoid possible cycle skipping and other anomalous effects.

Covariance and cross-correlation techniques need a preliminary assignment of start and final points, marking the signal time window of interest. As discussed by Crampin and Gao (2006), the choice of the time window for analysis is crucial for accuracy of the result. In particular, the first splitting parameter has to be evaluated in a signal window containing only the fast S-wave, i.e., where the polarization is roughly linear. Setting this value with no bias is possible only if we already know what the signals look like. Hence, we run the program with a first window guess and looked at the resulting $T_{\mathrm{d}}$ distribution. Then, we calibrated the window length on the characteristic time delay found for any particular group of seismic records. In the second parameter estimation, however, the use of cross-correlation function requires signals longer than a period and short enough to not include other phase arrivals later than the S-waves. Our algorithm estimates the S-wave cycle length from the power spectrum calculated over a time window of length $\left[t_{\mathrm{p}} ; t_{\mathrm{p}}+t_{\mathrm{s}}+0.5 \mathrm{~s}\right]$. We check the stability of the results trying different window lengths. Summarizing, our algorithm needs the definition of two time windows calibrated on signal characteristics (an example is in Fig. 1). Such semi-automation allows more accurate and objectively reliable results with no loss in terms of data number, since the selection is operated (manually) in the preliminary step of the analysis. Furthermore, it permits us to process more data at the same time producing results in quasi-real time.

We use this procedure to calculate the shear wave splitting parameters for some dataset collected on active volcanic areas in Italy. Most of these data have been already analyzed (Bianco et al. 1996, 1998a, b, 1999, 2004, 2006; Del Pezzo et al. 2004), constituting a useful validation test for the new algorithm, as we applied it exactly on the same number of data previously selected by those authors, following the same selection rules. In order to compare the time delay values with the previous ones and also those of different volcanic areas, we estimated the anisotropy percentage $\xi$ defined following Savage et al. (1990): $\xi=\left(T_{\mathrm{d}} v_{\mathrm{s}} / D\right) \times 100$, where $T_{\mathrm{d}}$ is the time delay, $D$ the hypocenter distance, and $v_{\mathrm{s}}$ the S-wave velocity. The averaged $\xi$ represents an index that measures the mean degree of crustal anisotropy over all raypaths from earthquakes to station, and its general meaning is a quantification of both microcrack system density and aspect ratio in the surrounding rocks.

\subsection{Mt. Vesuvius}

Vesuvius is an active volcano, at present in a quiescent stage, located in the southern sector 


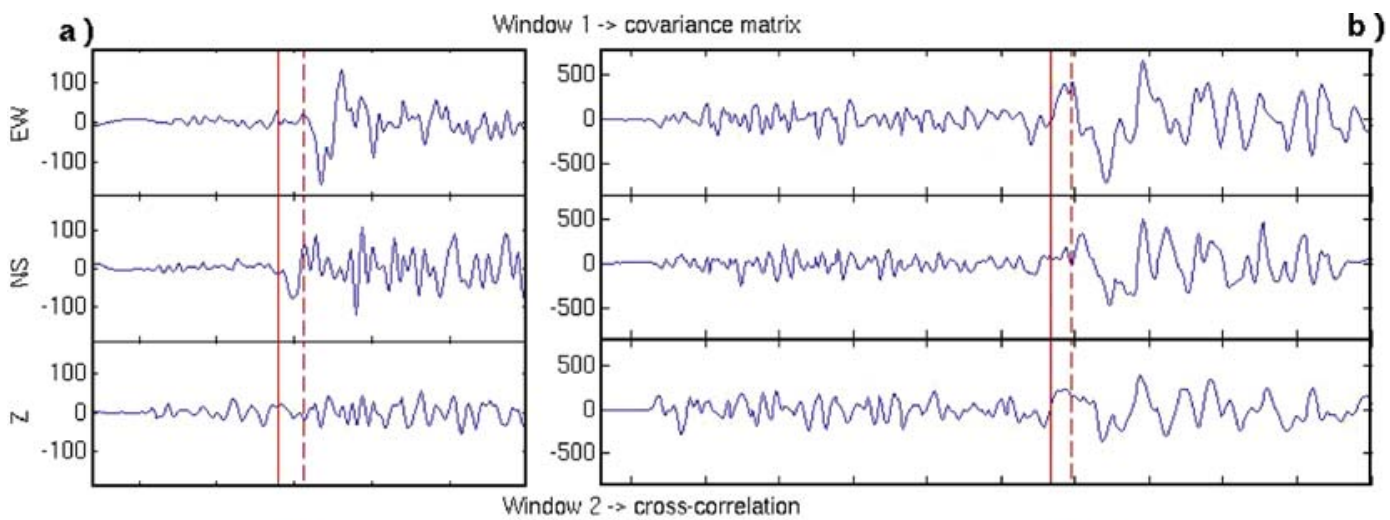

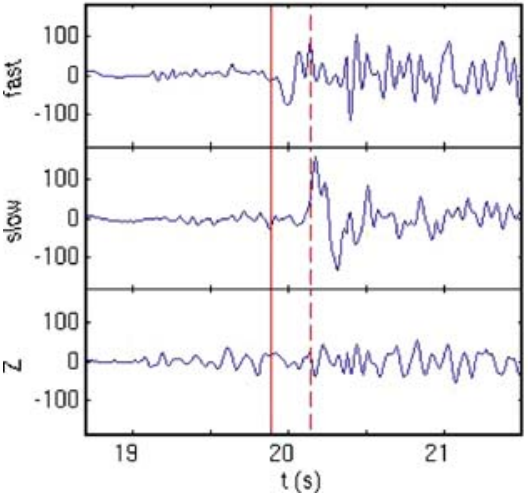

Fig. 1 Examples of the two window lengths as determined by the program for Mt. Etna (a) and Campi Flegrei (b) events. The straight line marks the beginning of the window (corresponding to S-wave arrival time minus two samples); the dotted one indicates the end. The upper panel shows the window chosen by the program to obtain $\varphi$ through

of the Campanian Plain. The last eruption occurred in March 1944 after about 300 years of semi-persistent activity and was an effusive eruption. Its activity began about 300-500 ky ago (Santacroce 1983). The volcanic edifice consists of an older, repeatedly collapsed strato-volcano (Somma), and a more recent cone (Vesuvius). The summit caldera resulted from several collapses related to Plinian (i.e., 79 A.D. "Pompei" eruption; Santacroce 1983) and/or sub-Plinian events (i.e., 1631 eruption; Rosi et al. 1987). The velocity structure beneath Mt. Vesuvius is well known and has been deduced by seismic tomography at different resolution scales (Auger et al. 2001; Scarpa et al. 2002). Moreover, the volcano seismicity pattern is described in many papers, from which we synthesize briefly the main features of earthquake spatiotemporal distribution: the seismicity covariance matrix decomposition. The bottom part of the figure shows the window inside which cross correlation has been calculated between the fast and slow components (after signal rotation of $\phi$ ). Seismograms are sampled at 100 and $200 \mathrm{~Hz}$, respectively

appears to extend down to $5 \mathrm{~km}$ below the central crater, with most of the energy clustered in a volume spanning $2 \mathrm{~km}$ in depth, positioned at the border between the limestone basement and the volcanic edifice. The earthquakes are of volcanotectonic type (VT, Chouet 1996), with fault plane orientations showing a highly non-regular spatial pattern. The spectral content of the P-and S-wave trains of the VT events is compatible with stress drops spanning an interval between 1 and 100 bars (100 bars for the highest duration Magnitude, 3.6) and focal dimensions of the order of $100 \mathrm{~m}$, apparently not scaling with the seismic moment (see Scarpa et al. 2002 and references therein). From 1965 to 2000, the seismicity showed an increase both in number and energy of events. The most energetic events occurred in March-April 1996 swarms when the largest number of earthquakes 
in the last 50 years were recorded (more than 670 events with $1<M<3.4 ; 0<$ depth $<6 \mathrm{~km}$ b.s.1.) and during the October 1999 seismic swarm that included a duration Magnitude of 3.6, the maximum since at least 1972, but possibly since last eruption in 1944. Overall, the seismicity of Mt. Vesuvius is characterized by a mean rate of 200 events per year.

\subsection{Data and results}

Only the data from two Lennartz 5800 digital 3D stations (BKE and BKN, Fig. 2; 125 s.p.s. with a dynamic range of $120 \mathrm{~dB}$ ) passed our selection rules and hence have been used for the shear wave splitting analysis. Records from these stations are available from the beginning of 1993 until the end of 2000. Due to the high-dynamic range, the signals are not clipped in the S-wave time window even for the largest magnitude event.
Unfortunately, the stations were not continuously operating during the analyzed period. By applying the procedure described in the previous section and using a $v_{\mathrm{s}}=1.8 \mathrm{~km} / \mathrm{s}$ for the first $2 \mathrm{~km}$, we obtained $\xi=4 \%$ for the background seismicity, i.e., for the seismicity excluding the two main crises of 1996 and 1999. In contrast, the same calculation performed on the data collected during the March-April 1996 and October 1999 swarms yield a value of $8 \%$ anisotropy. The polarization of the fast S-wave for the background seismicity is NS-oriented at BKN station and approximately EW-oriented at BKE station (Fig. 3). During the two main swarms, however, $\varphi$ strikes NS at BKE, suggesting the occurrence of a $90^{\circ}$ flip mechanism at the station closest to hypocenter locations.

The obtained values of splitting parameters are in agreement with previous works on the same earthquake data (Bianco et al. 1998a, 1999; Del Pezzo et al. 2004).
Fig. 2 The seismic network at Mt. Vesuvius; the location site of BKE and $\mathrm{BKN}$ stations are circled

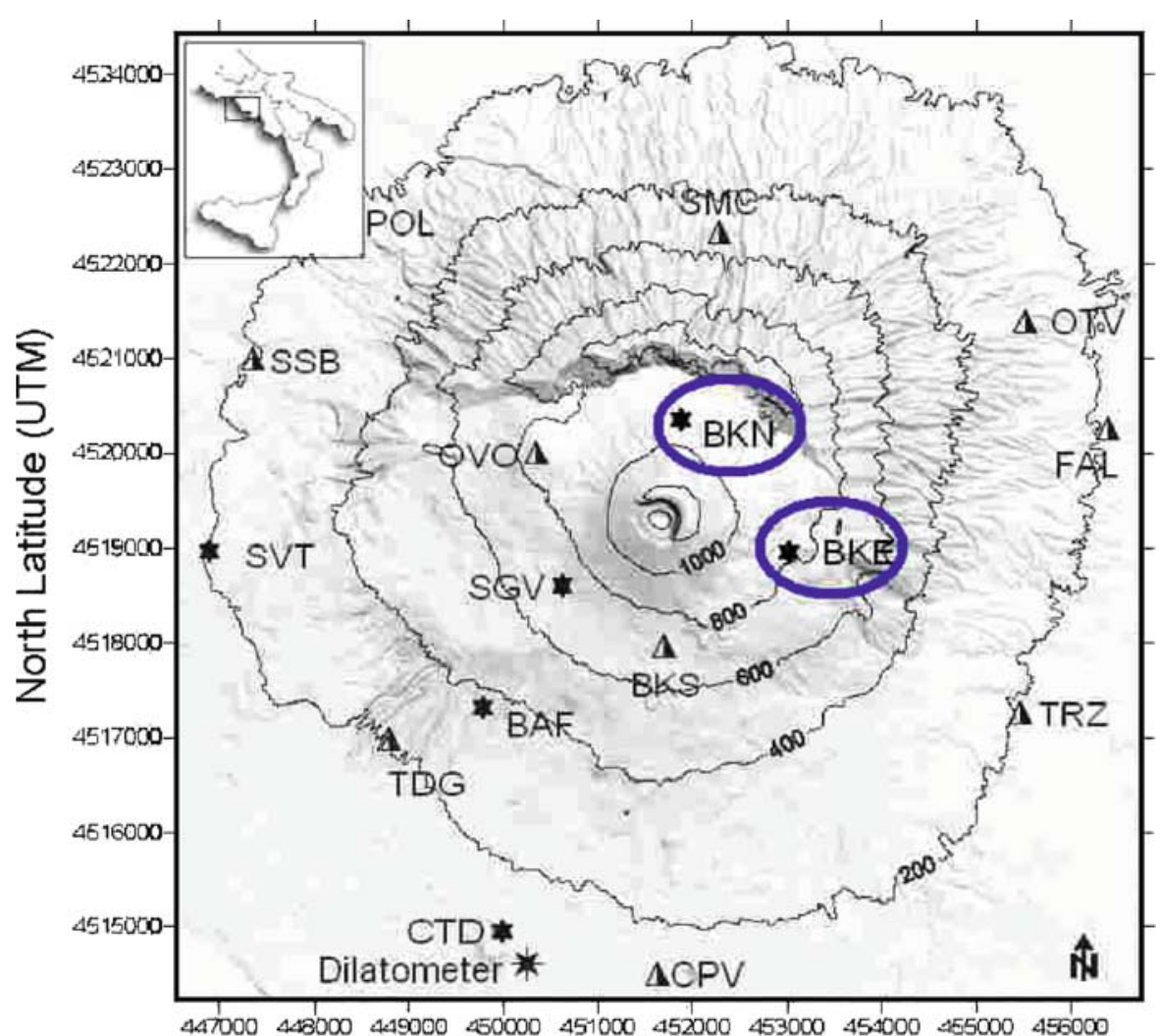

East Longitude (UTM) 
Fig. 3 a Equal-area rose diagrams for the fast polarization direction at BKE and BKN for all the investigated seismicity; b the same at BKE plotted only for data collected during the 1996 and 1999 crisis. The average fast polarization direction rotates through $90^{\circ}$ at BKE during these crises
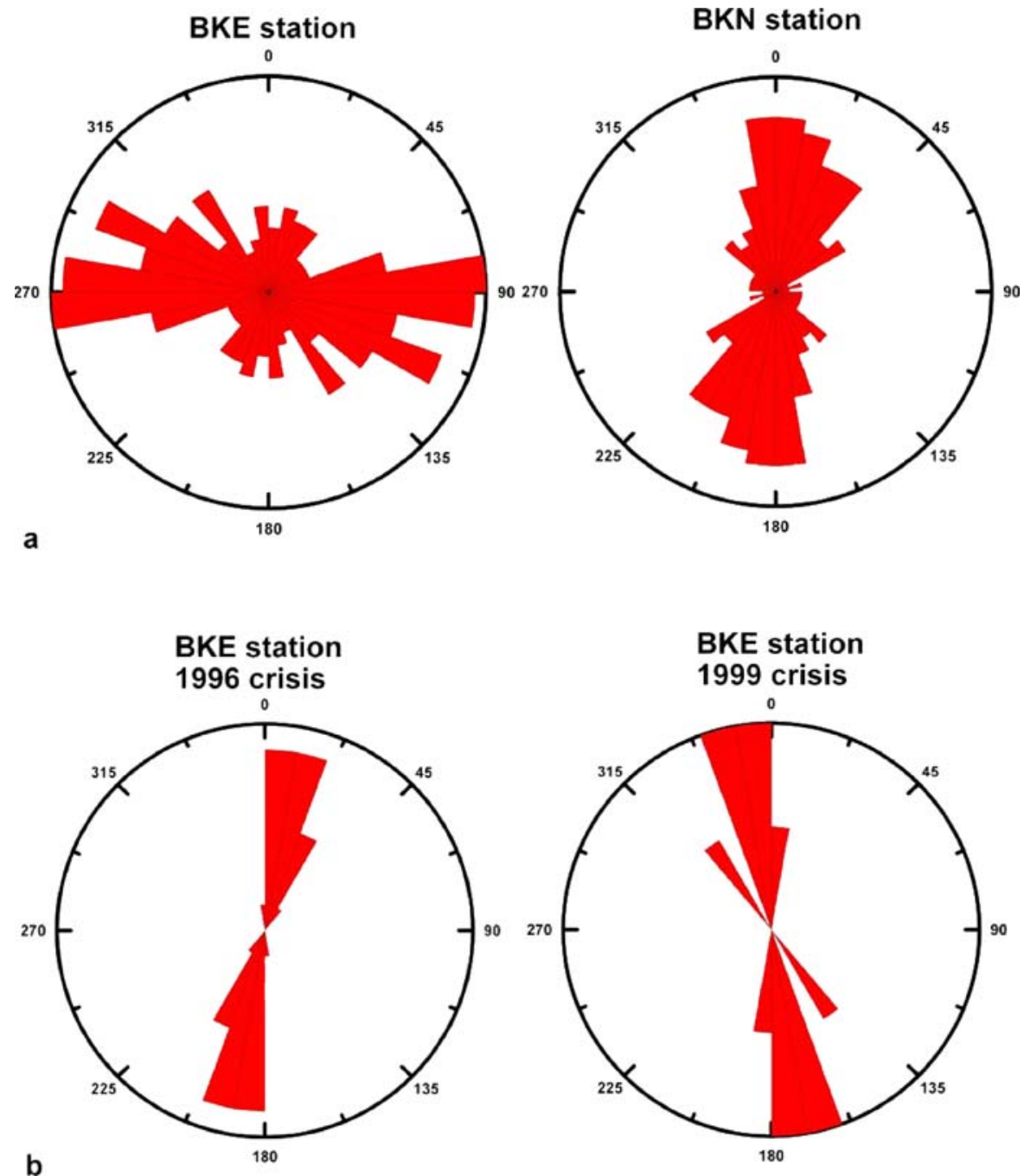

\subsection{Campi Flegrei}

Campi Flegrei (CF) volcanic complex is a nested caldera located in a densely populated area $(\sim 1.5$ million inhabitants) west of Naples, Southern Italy. The distance between Campi Flegrei and Mt. Vesuvius is less than $20 \mathrm{~km}$. CF evolution has been characterized by many eruptive episodes, the most important being the large Campanian Ignimbrite (40 ky ago) and the Neapolitan Yellow Tuff (15 ky ago) eruptions (Scandone et al. 1991); the last one dates back to 1538 A.D., with the Monte Nuovo eruption (Di Vito et al. 1999).

The most prominent feature of CF activity is the worldwide-known phenomenon called "bradyseism" consisting of slow subsidence interrupted by phases of noticeably faster ground uplift. Recently, a major bradyseismic crisis occurred in 1982-1984, during which a net uplift of $1.8 \mathrm{~m}$ centered on the town of Pozzuoli was accompanied by more than 16,000 earthquakes $\left(M_{\text {Max }}=\right.$ 4.0) mostly located beneath the Pozzuoli-Solfatara area (Fig. 4) at depths between 0 and $4 \mathrm{~km}$ b.s.l. (Aster et al. 1992). These earthquakes were recorded by the first digital high-dynamic range mobile seismic network, providing an invaluable data set, still being analyzed, that has allowed a wide researcher community to investigate both the subsurface velocity structure and the dynamics of the seismic source. 


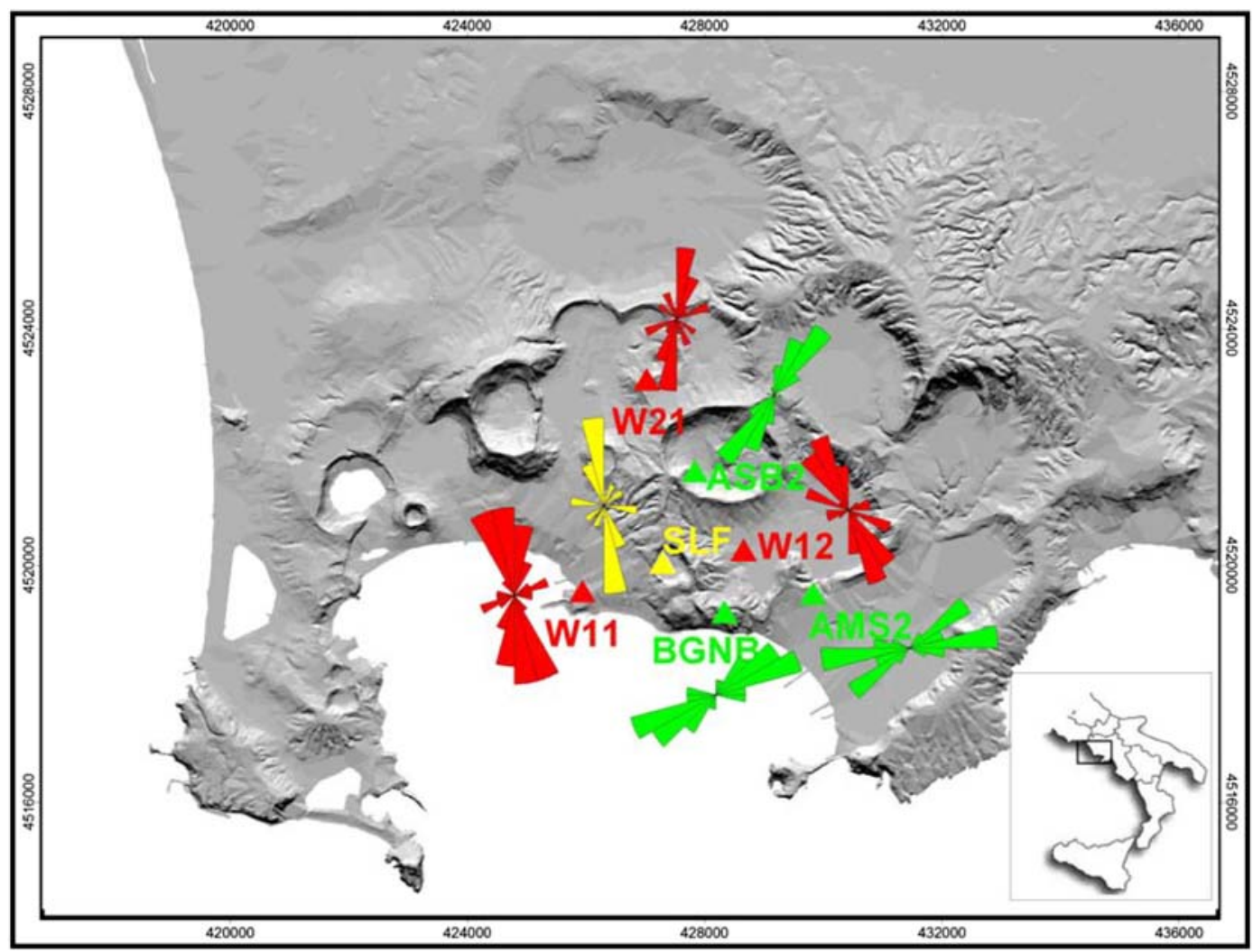

Fig. 4 Rose diagrams of the fast polarization direction at Campi Flegrei area; stations and results for datasets 1, 2, and 3 are identified by the colors red, yellow, and green, respectively

Since January 1985, the area has undergone a phase of general subsidence interspersed by minor short-duration uplifts which occurred on 1989, 1994, 2000, and 2004. A characteristic of these movements is that seismicity always accompanies the uplift phases, while the subsidence occurs aseismically (Saccorotti et al. 2001). On July-August 2000, the ground deformation reached a maximum value of about $4 \mathrm{~cm}$, and a swarm of low-magnitude VT earthquakes occurred in a period of 3 months. After August 2000, subsidence renewed, and according to geodetic observation, this phase stopped on November 2004 with the onset of a new uplift episode reaching a level of about $4 \mathrm{~cm}$ by the end of October 2006 (Troise et al. 2007). This last phase shows an uplift rate lower than that of 2000, and at the present days, the very last ground deformation measurements seem to indicate a general cessation of the phenomenon. Remarkable swarms of both VT and LP (Long Period, Chouet 1996) earthquakes have accompanied this last ground uplift, with the highest number of seismic events ever recorded since 1985 (Saccorotti et al. 2007).

\subsection{Data and results}

We measured the splitting parameters for earthquakes which occurred during the 1982-1984 (dataset 1), 2000 (dataset 2), and 2004-2006 (dataset 3) crises.

Concerning dataset 1, 80 earthquakes recorded at three stations (W11, W12, and W21, see Fig. 4) passed our selection rules; the depths of the selected seismicity mainly spans the first 3-4 km of the upper crust. By applying the semiautomatic algorithm and using a $v_{\mathrm{s}}=1.7 \mathrm{~km} / \mathrm{s}$ for the first $2 \mathrm{~km}$, we calculated that $\xi$ is $7 \%$. Spatially, the polarization of the fast wave shows an irregular pattern: the polarization is approximately 
NNW/SSE-oriented at W11 and W12 stations, and NNE/SSW-oriented at W21 station (Fig. 4). Savage et al. (1989) studied the shear wave splitting at Campi Flegrei for 51 microearthquakes that occurred during the 1984 bradyseismic crisis. They too processed data from station W11, located just at the center of the caldera, finding a minimum anisotropy of $7 \%$ and a fast shear wave orientation striking NNE-SSW, values that are compatible with our results.

For dataset 2, 19 events recorded at the digital station SLF (Fig. 4) passed the selection rules. By applying the semiautomatic algorithm, we determined that the fast polarization strikes mainly NNW-SSE, confirming the orientation retrieved by Bianco et al. (2004). With the same S-velocity of $1.7 \mathrm{~km} / \mathrm{s}$ for the first $2 \mathrm{~km}$, we calculated $\xi$ to be about $4 \%$. This value is perfectly comparable with those observed at the Californian Geysers geothermal field (Evans et al. 1995) and at Long Valley caldera (Savage et al. 1990), but is lower than the value found by Savage et al. (1989) at Campi Flegrei and in this study for dataset 1.

For dataset 3, 20 earthquakes recorded at three stations (ASB2, AMS2, and BGNB, Fig. 4) passed our selection rules. The three stations are digital high-dynamic Lennartz M-24/Lennartz MarsLite equipped with broadband sensors (LE-3D $20 \mathrm{~s} /$ Guralp CMG $40 \mathrm{~s}$ ). By applying the semiautomatic algorithm, we determined that the fast polarization strikes approximately NNW-SSE at ASB2 and NE-SW at AMSE and BGNB stations. Using a $v_{\mathrm{s}}=1.7 \mathrm{~km} / \mathrm{s}$ for the first $2 \mathrm{~km}$, we found an anisotropy percentage of $3 \%$, which is the lowest value we retrieved in the Campi Flegrei area.

The difficulty in discussing these results is that we cannot distinguish between background and crisis seismicity, since at Campi Flegrei, as highlighted above, earthquakes occur only during the uplift crisis.

\subsection{Mt. Etna}

Mt. Etna volcanic activity, mainly characterized by effusive basaltic eruptions, began around 0.7 My ago, continuing almost uninterruptedly until the present. The volcano has developed at the intersection of two regional tectonic lineaments, the NNW-SSE trending Hybleo-Maltese escarpment, which separates the thick inland continental crust of the African platform from the Ionian Mesozoic oceanic crust, and the NE-SW Messina-Fiumefreddo fault that marks a rift zone between south Calabria and northeastern Sicily extending as far as the volcanic area. All these tectonic features affect the morphology, especially of the eastern side of the volcano (Bonforte and Puglisi 2006 and references therein). The volcanic activity is always accompanied by the occurrence of seismicity. Earthquakes may also happen independently from magma movements due to the dynamics of the several active faults through the volcano.

\subsection{Data and results}

Shear wave splitting parameters have been investigated several times during different periods of activity. Bianco et al. (1996) measured the splitting parameters on a data set collected in spring-summer 1988, a period with no eruption. Eleven earthquakes recorded at 10 stations, all located on the eastern sector, passed the selection rules, and the selected events occurred in the first $10-15 \mathrm{~km}$ of the upper crust, with magnitude between 2.3 and 3.1. The stations were digital high-dynamic Lennartz PCM 5800 equipped with $1 \mathrm{~Hz}$ Mark L4C-3D and $2 \mathrm{~Hz}$ Mark L4A-3D sensors. The authors found that the fast polarization at all stations strikes, approximately, in the NS direction, which is the direction of the maximum compressive stress deduced for the area. We applied our semiautomatic procedure on subset of the data investigated by Bianco et al. (1996), consisting of 10 events recorded at two stations (DMT and POM, Fig. 5). The fast polarization strikes in NS direction at both stations (Fig. 6), as found previously. Using a $v_{\mathrm{s}}=2.2 \mathrm{~km} / \mathrm{s}$ for the first $8 \mathrm{~km}$, we calculated that the background $\xi$ averages $1.5 \%$.

A similar seismic network was installed again on the eastern sector of the volcano during MayNovember 1989; this period includes the occurrence of the September-October eruption. We calculated the splitting parameters for the signals collected at two stations of this network (NOC and CCV, in Fig. 5). Ten earthquakes passed the selection rules; again, the selected events sampled 

stations that collected data on Mt. Etna analyzed in this study. The stations operated in different periods: DMT and POM operated in 1988 when no eruption occurred; NOC, CCV, and $\mathrm{B} 92$ collected data including seismicity that occurred during 1989 eruption; MNT and ESP operated during the 2001 eruption
Fig. 5 Map of the seismic

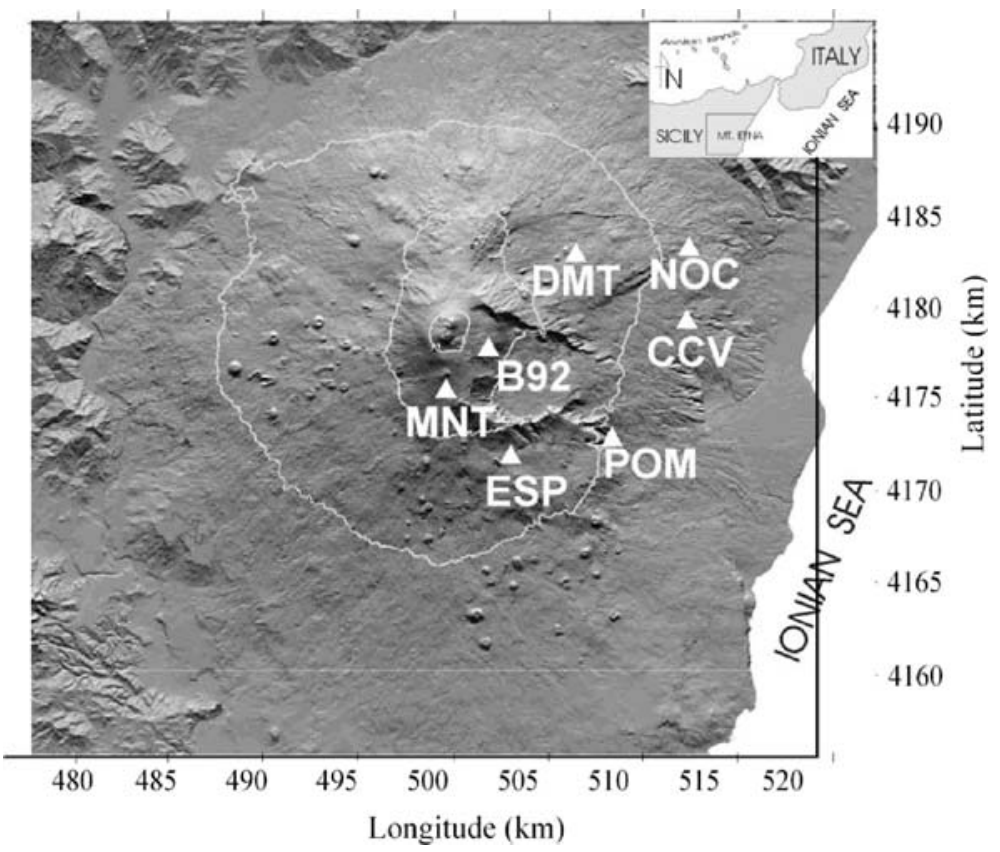

the first $10-15 \mathrm{~km}$ of the upper crust, with magnitude between 2.1 and 3.5. At all the stations, $\varphi$ is confirmed in the NS direction (Fig. 7), while the anisotropy, considering the same mean velocity, averages $3 \%$.

During the 1989 eruption, a NNW/SSEoriented fracture system opened at 2,700 $\mathrm{m}$ above sea level (September 27) and propagated $6.5 \mathrm{~km}$ downslope to $1510 \mathrm{~m}$ a.s.l. (October 3). Bianco et al. (1998b) performed shear wave splitting analyses during the propagation of the fracture system in order to study the correlation between seismic anisotropy and the syn-eruptive cracking process. Due to the selection rules, the available dataset was reduced to 13 earthquakes collected at one (B92) digital high-dynamic Lennartz PCM 5800 equipped with $1 \mathrm{~Hz}$ Mark L4C sensor. The $\mathrm{qS}_{1}$ polarization strikes NE-SW, i.e., almost orthogonal to the strike of the NNW-SSE fractures nearest B92 and subparallel to the ENE-WSW
Fig. 6 Rose diagrams at Mt. Etna for the 1988 dataset at stations DMT and POM
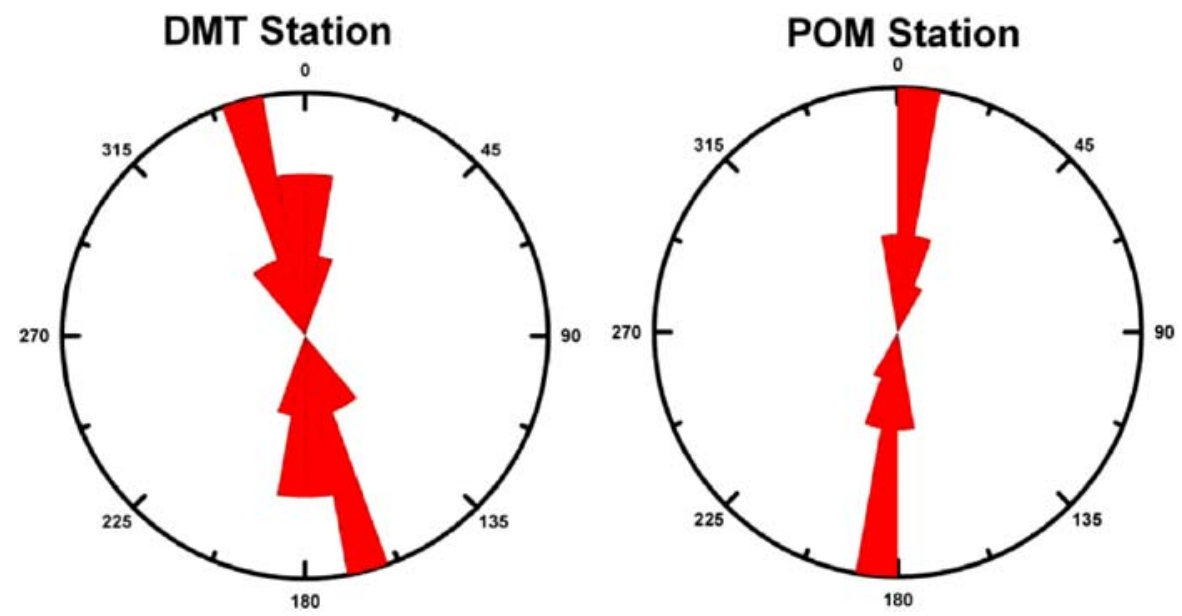

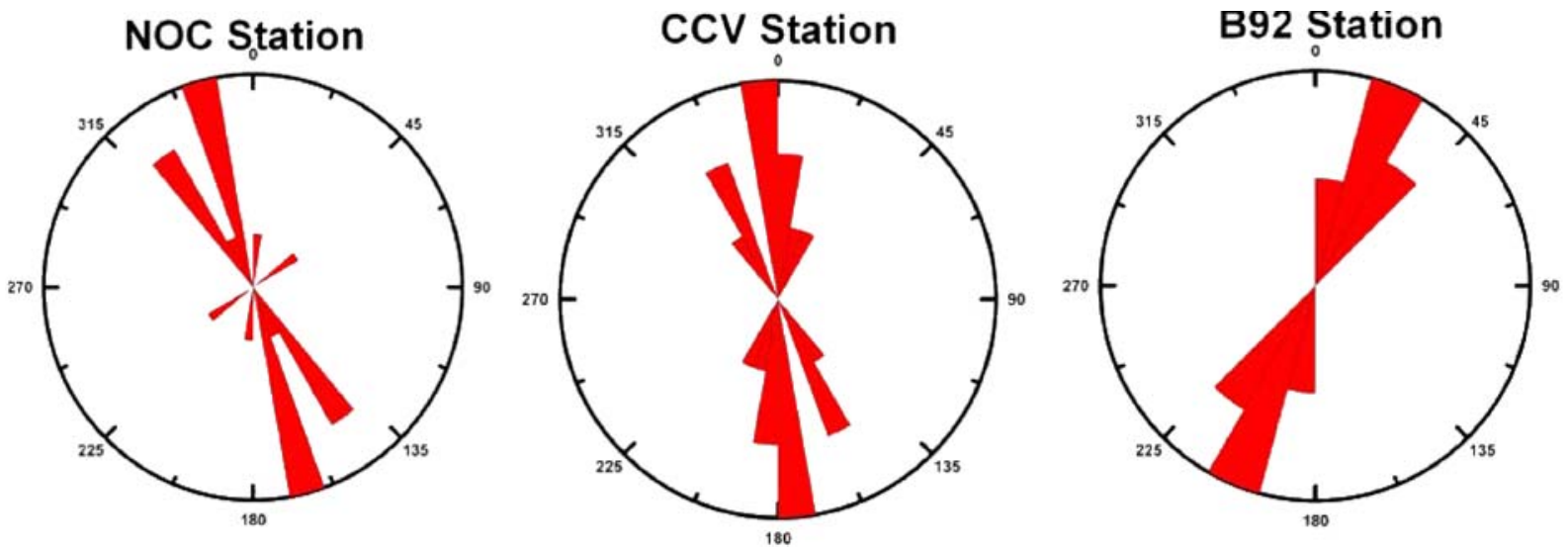

Fig. 7 Rose diagrams at Mt Etna for the 1989 dataset at stations NOC, CCV, and B92

cracks associated to the folds. Interestingly, the delay between the split waves exhibited a time-related trend with the fracture propagation (Bianco et al. 1998b). Applying our semiautomatic procedure, we confirm the ENE-WSW orientation for the fast $\mathrm{S}$-wave (Fig. 7). Using a $v_{\mathrm{s}}=$ $1.2 \mathrm{~km} / \mathrm{s}$ for the first $2 \mathrm{~km}$, the anisotropy for this dataset is around $6 \%$.

Lastly, we applied the semiautomatic algorithm to infer the splitting parameters for 134 earthquakes which occurred during 2001 in a period including the July eruption. This dataset was collected at two digital high-gain 3C seismic stations MNT and ESP (Fig. 5). Our procedure returns for the complete set of data $\mathrm{qS}_{1}$ polarization directions striking approximately NNW-SSE at both ESP and MNT stations (Fig. 8), in agreement with the results of Bianco et al. (2006). The nearly EW polarizations at MNT occur mostly in the period immediately before the eruption when there are $90^{\circ}$ flips in shear wave polarizations (see Fig. 3b in Bianco et al. 2006). We took a $v_{\mathrm{s}}=$ $2.2 \mathrm{~km} / \mathrm{s}$ over the first $5 \mathrm{~km}$ to calculate a $\xi$ value of $4.4 \%$.

The temporal variation of the splitting parameters during the occurrence of the 2001 eruption has been widely investigated, for the same dataset, by Bianco et al. (2006). These authors found that the normalized time delays show a systematic increase starting several days before the
Fig. 8 Rose diagrams at Mt. Etna for the 2001 dataset at stations MNT and ESP
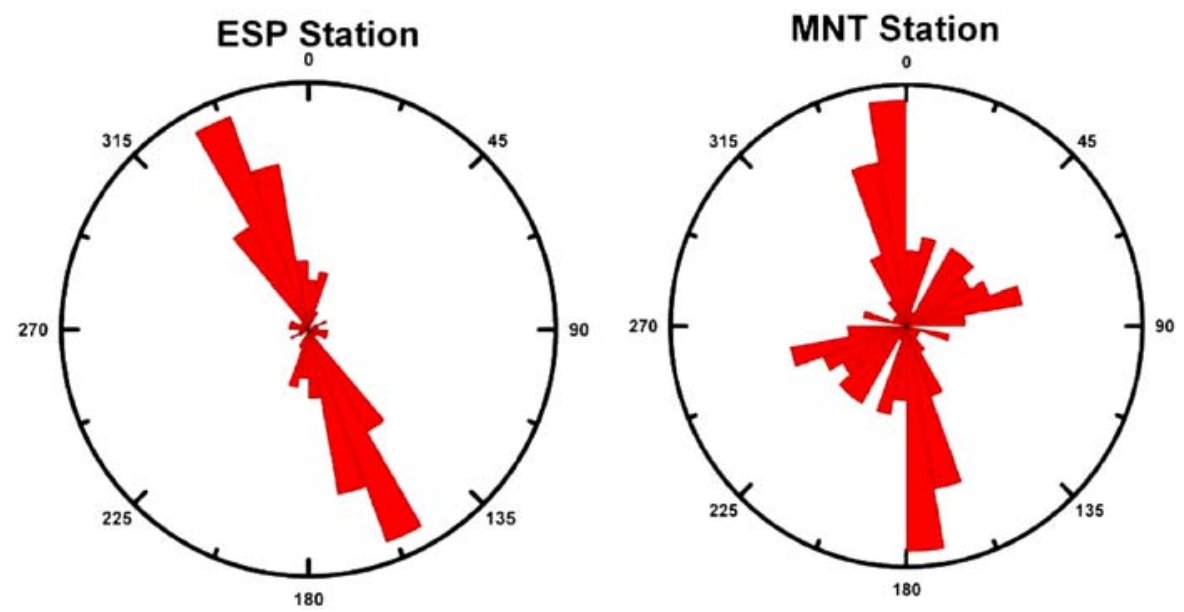
onset of the eruption (July 17). The time delays also exhibit a sudden decrease shortly before the start of the eruption, suggesting the possible occurrence of a 'relaxation' phenomenon due to crack coalescence. This behavior has many similarities to that observed before a number of earthquakes elsewhere (Gao and Crampin 2004). On several occasions before Etna activity onset, the $\mathrm{qS}_{1}$ polarization directions at the stations closest to the eruption show $90^{\circ}$ flips, meaning that faster and slower shear waves exchange their polarizations. In particular, the unflipped $\varphi$ strikes approximately in NS direction, as always observed at Mt. Etna.

\section{Discussions and conclusions}

Three Italian active volcanoes have been investigated in order to assess their anisotropic features through the implementation of a semiautomatic algorithm applied to all the available datasets and also to check the association between temporal variations of splitting parameters and the occurrence of changes in the dynamic pattern of the volcanic activity. As recommended by Gao et al. (2006), the semiautomatic techniques need user control at a particular step of the analysis (in our case the window length calibration). However, our algorithm has been designed to manage a huge quantity of very high-quality data (preselected), unlike SWAS (Gao et al. 2006), which allows processing of all the small earthquakes. As suggested by Crampin and Gao (2006), rejecting many records may lead to bias. However, due to the complexity of the waveforms collected in volcanic areas that are generally contaminated by the superposition of signals originated by the volcanic and/or hydrothermal dynamic, we preferred to apply severe selection rules on the analyzed dataset to reduce the risks of misinterpretations. Consequently, we measured the splitting parameters on signals showing clear shear wave onsets with high signal-to-noise ratios $(\mathrm{S} / \mathrm{N}>6)$ and incidence angles strictly inside the shear wave window (theoretically $35^{\circ}$ ). Moreover, all the selected data, after having been processed with the quasiautomatic analyses, passed the final hodograms check, so we did not reject any data at the final stage. As well known, an irregular surface topography severely distort the shear-wave window; we did not take into account this effect in our study, since all the stations we analyzed are installed in locally flat areas .

We found that at Mt. Vesuvius, the fast polarization direction strikes generally NS at BKN station and EW at BKE station; however, during the main seismic crisis which occurred in the last years (1996 and 1999), $\varphi$ observations at the station nearest the seismic source (BKE) are rotated toward the NS direction (Fig. 3b). This result confirms previous observations by Bianco et al. (1998a, 1999) and Del Pezzo et al. (2004) who analyzed the same dataset with different methodologies. The anisotropy percentage $\xi$ is $4 \%$ for the background seismicity. Conversely, the same calculation performed only on data collected during the March-April 1996 and October 1999 swarms yields $\xi=8 \%$.

In the Campi Flegrei area, the polarization of the fast wave shows an irregular pattern: for data collected during the 1982-1984 crisis, the $\mathrm{qS}_{1}$ polarization is approximately NNW/SSE-oriented at W11 and W12 stations and NNE/SSW-oriented at W21 station; for the 2000 crisis dataset, the fast polarization at station SLF strikes NNWSSE; for the 2004-2006 crisis the $\varphi$ direction is approximately NNW/SSE-oriented at ASB2 and NE-SW at AMSE and BGNB stations. The spatial distribution of the $\mathrm{qS}_{1}$ polarization appears to be complex (Fig. 4) and not easily interpretable. The anisotropy percentages span from $7 \%$ for dataset 1 , to $4 \%$ for dataset 2 , and $3 \%$ for the last dataset. The shear wave splitting parameters at Campi Flegrei have been investigated by (Savage et al. 1989) and by Bianco et al. (2004); both studies found results in agreements with the present paper.

At Mt. Etna, the fast polarization for all the investigated datasets strikes, on average, in the NS direction, which is the direction of the maximum compressive stress acting at regional scale (Musumeci et al. 2004). $\xi$ percentage is between $1 \%$ and $6 \%$, the lowest value pertaining to the 1988 dataset collected in a period with no eruption, the highest obtained for data sampling the 
opening of an eruptive fracture during the 1989 eruption. Our results are compatible with those obtained by Bianco et al. (1996, 1998b, 2006).

Different circumstances may produce the measured shear wave splitting. We reject the hypothesis that S-P conversion was responsible for the observed splitting because at vertical incidence, this type of conversion shows the greatest amplitude on the vertical component (Liu and Crampin 1990), whereas the whole analyzed data exhibit maximum amplitude in correspondence with the splitting on the horizontal components. We exclude the influence of aligned mineral grains on our measurements since the investigated volcanic areas are not underlain by tilted sedimentary or metamorphic rocks including these aligned minerals, at least at the depth sampled by our raypaths (Di Renzo et al. 2007; Bousquet and Lanzafame 2004). Waveforms that look like shear wave splitting (but are not) might be caused by complex source mechanisms (Zollo and Bernard 1989), but due to the low magnitude and small source dimension (presumed simple fault plane) of the events $\left(M_{\mathrm{MAX}}=3.6\right)$, we reject this hypothesis. For the above reasons, we suggest that the observed shear wave splitting is consistent with propagation through distribution of nearly vertical nearly parallel fluid saturated cracks striking in the direction of the neighboring system fractures. The same conclusions have been reached by the different authors that previously investigated most of the datasets analyzed in the present paper, as discussed in the other sections.

As suggested by Zatsepin and Crampin (1997), for $\xi \geq 5 \%$, a fracture criticality regime occurs. The measured values of anisotropy percentage may suggest that at Mt. Vesuvius, the fracture criticality regime has been reached during the 1996 and 1999 crisis; however, no eruption has been observed in these cases, the last eruption occurring on March 1944. At Campi Flegrei, the fracture criticality regime has been reached during the 1982-1984 crisis, and in this case too, no eruption occurred. Interestingly, the percentage of anisotropy in this area decreases with time; possibly, this observation may be explained with a lower degree of fracturing in the upper crust with a different circulation of hydrothermal fluids for the three crisis. At Mt. Etna, the fracture criticality regime was reached during the opening of the 1989 eruptive fracture, but not during the 2001 eruption, even though $\xi$ assumes a borderline value. The correlation between reaching a fracture criticality regime and the occurrence of eruptions seems to be not straightforward for our datasets. The percentage of shear wave anisotropy and fracture criticality depend on several different factors such as Poisson's ratio, pore fluid velocity, and many others, being higher in areas of high heat flow (Crampin 1993). Our observations, on average, confirm this behavior, since we found normalized time delay generally greater than $10 \mathrm{~ms} / \mathrm{km}$.

However, a general increase of $\xi$ has been observed every time we analyzed data collected during volcanic crises in which significant movements of fluids have been documented (in particular at Mt. Vesuvius and Campi Flegrei, e.g., Bianco et al. 2004; Del Pezzo et al. 2004 and references therein). Our observations on the temporal variation of anisotropy percentages may account for a different regime in the fluid circulation favored by the critical opening of the stress aligned cracks, in agreement with the APE modeling (Zatsepin and Crampin 1997).

Acknowledgements Thoughtful comments from David Booth, Sheila Peacock, and an anonymous reviewer greatly helped to improve the quality of the manuscript. Work financed through the Italian Department of Civil Protection and INGV in the research framework programs in volcanology V4 (2006-2007) and the European Commission, 6th Farmework Project- "VOLUME", Contract No.08471.

\section{References}

Aster RC, Meyer RP, De Natale G, Zollo A, Martini M, Del Pezzo E, Scarpa R, Iannaccone G (1992) Seismic investigation of Campi Flegrei Caldera. Volcanic Seismology, Proceedings of Volcanology Series III. Springer, New York

Auger E, Gasparini P, Virieux J, Zollo A (2001) Seismic evidence of an extended magmatic sill under Mt. Vesuvius. Science 294:1510-1512

Bianco F, Castellano M, Milano G, Vilardo G (1996) Shear-wave polarization alignment on the eastern flank of Mt. Etna volcano (Sicily, Italy). Annali di Geofisica XXXXIX 2:429-443 
Bianco F, Castellano M, Milano G, Ventura G, Vilardo G (1998a) The Somma-Vesuvius stress-field induced by regional tectonic: evidences from seismological and mesostructural data. J Volcanol Geotherm Res 82:199-218

Bianco F, Castellano M, Ventura G (1998b) Structural and seismological features of the 1989 syn-eruptive NNWSSE fractures system at Mt. Etna. Geophys Res Lett 25(10):1545-1548

Bianco F, Castellano M, Milano G, Vilardo G, Ferrucci F, Gresta S (1999) The seismic crisis at Mt. Vesuvius during 1995 and 1996. Phys Chem Earth 24:977-983

Bianco F, Del Pezzo E, Saccorotti G, Ventura G (2004) The role of hydrothermal fluids in triggering the JulyAugust 2000 seismic swarm at Campi Flegrei (Italy): evidences from seismological and mesostructural data. J Volcanol Geotherm Res 133:229-246

Bianco F, Scarfî L, Del Pezzo E, Patanè D (2006) Shear wave splitting changes associated with the 2001 volcanic eruption on Mount Etna. Geophys J Int 167(2):959-967. doi:10.1111/j.1365-246X.2006.03152.x

Bonforte A, Puglisi G (2006) Dynamics of the eastern flank of Mt. Etna volcano (Italy) investigated by a dense GPS network. J Volcanol Geotherm Res 153: 357-369

Booth DC, Wyss M, Gillard D (1992) Shear-wave polarization alignments recorded above the Kaoiki fault zone, Hawaii. Geophys Res Lett 19:1141-1144

Bousquet JC, Lanzafame G (2004) The tectonics and geodynamics of Mt. Etna: synthesis and interpretation of geological and geophysical data. In: Bonaccorso A, Calvari S, Coltelli M, Del Negro C, Falsaperla S (eds) Etna Volcano Laboratory. AGU (Geophysical monograph series), pp 29-47

Chouet B (1996) New methods and future trends in seismological volcano monitoring. In: Scarpa R, Tilling RI (eds) Monitoring and mitigation of volcanic hazards. Springer, New York, pp 23-97

Crampin S (1993) A review of the effects of crack geometry on wave propagation through aligned cracks. Can J Explor Geophys 29:3-17

Crampin S, Zatsepin SV (1997) Modeling the compliance of crustal rock-II. Response to temporal changes before earthquakes. Geophys J Int 129:495-506

Crampin S, Gao Y (2006) A review of techniques for measuring shear-wave splitting above small earthquakes. Phys Earth Planet Inter 159:1-14

Crampin S, Peacock S, Gao Y, Chastin S (2004) The scatter of time delays in shear-wave splitting above small earthquakes. Geophys J Int 156:39-44

Del Pezzo E, Bianco F, Petrosino S, Saccorotti G (2004) Changes in coda decay rate and shear-wave splitting parameters associated with seismic swarms at Mt. Vesuvius, Italy. Bull Seismol Soc Am 94(2):439-452

Di Renzo V, Di Vito MA, Arienzo I, Carandente A, Civetta L, D'Antonio M, Giordano F, Orsi G, Tonarini S (2007) Magmatic history of SommaVesuvius on the basis of new geochemical and isotopic data from a deep borehole (Camaldoli della Torre). J Petrol 48(4):753-784
Di Vito MA, Isaia R, Orsi G, Southon J, de Vita S, D'Antonio M, Pappalardo L, Piochi M (1999) Volcanism and deformation since 12,000 years at the Campi Flegrei caldera (Italy). J Volcanol Geotherm Res 91:221-246

Evans JR, Julian BR, Foulger GR, Ross A (1995) Shearwave splitting from local earthquakes at The Geysers geothermal field, California. Geophys Res Lett 22: 501-504

Gao Y, Crampin S (2004) Observations of stress relaxation before earthquakes. Geophys J Int 157:578-582

Gao Y, Hao P, Crampin S (2006) SWAS: a shear-wave analysis system for semi-automatic measurement of shear-wave splitting above small earthquakes. Phys Earth Planet Inter 159:71-89

Gerst A, Savage MK (2004) Seismic anisotropy beneath Ruapehu volcano: a possible forecasting tool. Science 306:1543-1547

Liu E, Crampin S (1990) Effects of the internal shear wave window: comparison with anisotropy induced splitting. J Geophys Res 95(B7, 11):275-11281

Miller V, Savage MK (2001) Changes in seismic anisotropy after volcanic eruptions: evidence from Ruapehu. Science 293:2231-2233

Munson CG, Thurber CH, Li Y, Okubo PG (1995) Crustal shear wave anisotropy in southern Hawaii: spatial and temporal analysis. J Geophys Res 100:20367-20377

Musumeci C, Cocina O, De Gori P, Patanè D (2004) Seismological evidence of stress induced by dike injection during the $2001 \mathrm{Mt}$. Etna eruption. Geophys Res Lett 31:L07617. doi:10.1029/2003GL019367

Rosi M, Santacroce R, Sheridan MF (1987) Volcanic hazard. In: Santacroce R. (ed) Somma-Vesuvius. Quad Ric Sci 1141:197-234

Saccorotti G, Bianco F, Castellano M, Del Pezzo E (2001) The July-August 2000 seismic swarms at Campi Flegrei volcanic complex, Italy. Geophys Res Lett 28:2525-2528

Saccorotti G, Petrosino S, Bianco F, Castellano M, Galluzzo D, La Rocca M, Del Pezzo E, Zaccarelli L, Cusano P (2007) Seismicity associated with the 20042006 renewed ground uplift at Campi Flegrei caldera, Italy. Phys Earth Planet Inter 165(2):14-24

Santacroce R (1983) A general model for the behaviour of the Somma-Vesuvius volcanic complex. J Volcanol Geotherm Res 17:237-248

Savage MK, Shih XR, Meyer RC, Aster RC (1989) Shearwave anisotropy of active tectonic regions via automated S-wave polarization analysis. Tectonophysics 165:279-292

Savage MK, Peppin WA, Vetter UR (1990) Shear wave anisotropy and stress direction in and near Long Valley caldera, California, 1979-1988. J Geophys Res 95:11165-11177

Scandone R, Bellucci F, Lirer L, Rolandi G (1991) The structure of the Campanian Plain and the activity of Neapolitan volcanoes. J Volcanol Geotherm Res 48:1-31

Scarpa R, Tronca F, Bianco F, Del Pezzo E (2002) High resolution velocity structure beneath Mt. Vesuvius 
from seismic array data. Geophys Res Lett 29(21): 2040. doi:10029/2002GL015576

Troise C, De Natale G, Pingue F, Obrizzo F, De Martino P, Tammaro U, Boschi E (2007) Renewed ground uplift at Campi Flegrei caldera (Italy): new insight on magmatic processes and forecast. Geophys Res Lett 34:L03301. doi:10.1029/2006GL028545

Volti T, Crampin S (2003) A four-year study of shear-wave splitting in Iceland: 2-Temporal changes before earthquakes and volcanic eruptions. In: Nieuwland R (ed)
New insights into structural interpretation and modelling. Geological Society Special Publication 212, pp 135-149

Zatsepin SV, Crampin S (1997) Modeling the compliance of crustal rock-I. Response of shear-wave split ting to differential stress. Geophys J Int 129:477-494

Zollo A, Bernard P (1989) S-wave polarization inversion of the 15 October 1979, 23:19 imperial valley aftershock: evidence for anisotropy and a simple source mechanism. Geophys Res Lett 16:1047-1050 